\title{
Role of intestinal microflora in initiation and perpetuation of inflammatory bowel disease
}

RB SARTOR, MD

\begin{abstract}
Ulcerative colitis and Crohn's disease occur in regions of the intestine colonized by the highest concentrations of normal flora bacteria and resemble certain chronic bacterial, viral or parasitic infections. However, the role of endogenous and pathogenic bacteria in the induction and perpetuation of chronic idiopathic intestinal inflammation remains controversial. No convincing evidence incriminates a single bacterial, mycobacterial or viral agent as the cause of a high percentage of cases of idiopathic inflammatory bowel disease (IBD). Subtle alterations of luminal microbial flora are nearly impossible to detect, but concentrations of certain anaerobic bacteria, including Bacteroides vulgatus, are increased in active Crohn's disease and correlate with disease activity. Recent investigations suggest mechanisms which bacteria may induce an autoimmune response through molecular mimicry or alterations in host antigens or immunoregulation. Intestinal bacteria contain formylated peptides and cell wall polymers (endotoxin and peptidoglycan-polysaccharide complexes) which have potent and well characterized inflammatory and immunoregulatory properties and can produce acute and chronic intestinal and systemic inflammation in experimental animals. These proinflammatory molecules are probably absorbed more readily in IBD due to increased mucosal permeability during active and perhaps quiescent phases of disease. While the primary mechanisms of intestinal injury remain unknown, it is likely that commensal bacteria and their products amplify and perpetuate the inflammatory response of IBD and may be responsible for extraintestinal manifestations in addition to the frequent septic complications of these diseases. Can J Gastroenterol 1990;4(7):271-277 (pour résumé, voir page 272)
\end{abstract}

Key Words: Crohn's disease, Etiology, Microbiology, Ulcerative colitis

Division of Digestive Diseases, Chapel Hill, North Carolina, USA

Correspondence and reprints: Dr R Balfour Sartor, Associate Professor of Medicine, Immunology and Microbiology, Division of Digestive Diseases, CB \#7080, Room 465, Bumett-Womack Building, University of North Carolina, School of Medicine, Chapel Hill, NC 27599-7080, USA. Telephone (919) 966-2511
E XTENSIVE CIRCUMSTANTIAL EVIdence links the intestinal microflora and luminal contents to inflammatory bowel disease (IBD). Ulcerative colitis and Crohn's disease occur in intestinal regions colonized by the highest bacterial concentrations; Crohn's disease improves when luminal bacterial concentrations are diminished by bowel rest, bypass, lavage and broad spectrum and anaerobic antibiotics; and a generalized increased mucosal permeability permits enhanced uptake of viable bacteria, bacterial products and luminal antigens. The inflammatory response of IBD resembles chronic infection of the intestine. The gross and histologic appearance of ulcerative colitis is quite similar to Campylobacter jejuni, shigella, amebic and cytomegalovirus colitis, while Crohn's disease is indistinguishable histologically from mycobacterial, yersinia or chlamydial infections. Normal intestinal bacteria flora and hence the distal ileal and entire colonic lumen contain formylated peptides and cell wall polymers with potent and well characterized inflammatory and immunoregulatory properties. These bac- 


\section{Rôle de la microflore intestinale dans l'instauration et le maintien des maladies inflammatoires de l'intestin}

RESUME: La colite ulcéreuse et la maladie de Crohn surviennent dans les régions de l'intestin où les bactéries de la flore normale sont les plus fortement concentrées; elles ressemblent à certaines infections chroniques d'origine bactérienne, virale ou parasitique. Pourtant, le rôle des bactéries endogènes et pathogènes dans l'induction et le maintien de l'inflammation idiopathique chronique de l'intestin reste controversé. Aucune preuve convaincante ne semble incriminer un seul agent bactérien, mycobactérien ou viral, ni lui attribuer la responsabilité d'un pourcentage élevé des cas des MII idiopathiques. Si les altérations subtiles de la flore microbienne au niveau des lumières sont presque impossible à déceler, on note par contre des concentrations élevées de certaines bactéries anaérobiques, Bacteroides vulgatus entre autres, dans la maladie de Crohn en évolution; on relève une corrélation entre cette pullulation bactérienne et l'activité de la maladie. Des études récentes suggèrent les mécanismes selon lesquels les bactéries pourraient déclencher une réponse autoimmune agissant par mimétisme moléculaire, par altération des antigènes de l'hôte ou immunorégulation. Les bactéries de la flore contiennent des peptides formylés et des polymères provenant des parois bactériennes (endotoxines et complexes peptidoglycan-polysaccharide), dotés de propriétés inflammatoires et immunorégulatoires puissantes et bien caractérisées. Elles peuvent provoquer des inflammations aiguës, chroniques et systémiques chez les modèles expérimentaux. Ces molécules sont probablement absorbées plus aisément dans les MII à cause de la perméabilité accrue de la muqueuse au cours des phases actives et peut-être même dormantes. Si les mécanismes primaires des lésions intestinales sont toujours inconnus, il est probable que les bactéries commensales et leurs produits soient responsables à la fois des manifestations extra-intestinales et des complications septiques fréquentes dans les MII.

terial products can produce acute and chronic intestinal and systemic inflammation in experimental animals. Germ-free and decontaminated rodents are much less sensitive to toxic, ischemic and radiation injury than normals. Although the primary insult which initiates intestinal injury remains unknown, it is likely that commensal bacteria and their products amplify and perpetuate the inflammatory response in IBD and may be responsible for extraintestinal manifestations. This paper discusses mechanisms by which normal intestinal microflora and microbial pathogens may cause IBD and experimental chronic enterocolitis.

\section{MECHANISMS OF INTESTINAL MICROFLORA-INDUCED INFLAMMATION}

Acute and chronic inflammation of IBD arises from an unrestrained immunologic reaction to an unknown antigen. The chronic recurrent nature of the inflammation suggests either a per- sistent or ubiquitous triggering agent. However, the origin of the continuous activation of the immune system and the nature of the inciting antigen(s) are unknown. Is IBD an appropriate response to an abnormal environmental antigen (pathogenic microbe or toxic luminal constituent) or a hyperactive response to normal antigens? It is entirely possible, indeed probable, that both Crohn's disease and ulcerative colitis are heterogeneous diseases with multiple etiologies that appear similar because of a limited repertoire of the intestinal inflammatory response. Even if initiating events differ, these patients may exhibit the common thread of a genetically determined defect in immunoregulation. Clearly ulcerative colitis and Crohn's disease have different manifestations and must be considered separately.

Table 1 lists current theories of pathogenesis of ulcerative colitis and Crohn's disease. The possible impact of intestinal microflora on each theory is discussed below. This discussion con-
TABLE 1

\section{Theories of inflammatory bowel dis-} ease etiology

Toxic response to luminal contents Specific microbial pathogen

Abnormal luminal constituents

Increased absorption of luminal macromolecules

Enhanced immunological response to normal constituents

Autoimmune response

To epithelial cell or mucus glycoproteins

Molecular mimicry (cross-reactivity of intestinal microflora and epithelia) To immune cells

centrates on newer observations as this subject has been extensively reviewed $(1,2)$.

\section{TOXIC RESPONSE TO}

\section{LUMINAL CONTENTS}

Specific microbial pathogen: The simplest explanation for the etiology of IBD and best hope for a specific cure is that a single pathogenic organism in. itiates and perpetuates inflammation. Extensive epidemiological, microbiological, immunological and therapeutic investigations fail to support a role for conventional bacterial, viral or parasitic enteric pathogens, cell wall defective bacteria ( $\mathrm{L}$ forms), plasmids or lymphotropic viruses as causative agents of either disease $(1,2)$. The only currently viable candidate for a specific pathogen is Mycobacterium paratuberculosis in Crohn's disease (3). Identical organisms by DNA analysis have been isolated from at least seven resected Crohn's disease tissues by four separate centres. Other evidence supports this theory: Crohn's disease resembles intestinal tuberculosis; spontaneously occurring granulomatous enterocolitis caused by $M$ paratuberculosis occurs in ruminants (Johne's disease); and a human isolate has caused ileal granulomas in a neonatal goat. A pathogenic strain of $M$ avium $\left(A_{1}\right)$ which causes approximately $5 \%$ of Johne's disease cases has been isolated from two patients with Crohn's disease and one ulcerative colitis specimen from two different locations (4). However, isolation rates for all types of mycobacteria have been low even in the most expert centres (four of 28 
TABLE 2

\begin{tabular}{l} 
Episodic infections which can \\
produce reactivation/exacerbation \\
of inflammatory bowel disease \\
\hline Clostridium difficile \\
Mycobacteria \\
Campylobacter \\
Aeromonas \\
Respiratory infections \\
Cytomegalovirus \\
Escherichia colishigatoxin and \\
verocytotoxin
\end{tabular}

specimens by Chiodini et al [3]), and there is no convincing humoral or cellular immune response to the organism in Crohn's disease patients (5). Carefully performed immunohistochemical staining (6), in situ hybridization and DNA homology studies have been negative, and response to appropriate antibiotics is controversial, but certainly not curative. In addition, no clinical or epidemiological evidence supports mycobacteria as a cause of Crohn's disease. For example, disease activity improves with immunosuppressive therapy (steroids, 6-methylprednisolone, etc) and human immunodeficiency virus (HIV) infection (7). Current evidence makes this theory unlikely, unless only a small subset of Crohn's disease is induced by M paratuberculosis. Careful identification of spheroplasts, which are consistently recovered from 30 to $40 \%$ of Crohn's disease tissues but very few control specimens, is currently being performed using polymerase chain reaction technology, which should confirm or refute the mycobacterial theory.

Although no convincing evidence of chronic infection with a conventional pathogen currently exists, recent discoveries of Clostridium difficile toxininduced colitis, legionella, HIV, cryptosporidium, microsporidia, Borrelia burgdorferi (Lyme disease), Escherichia coli 0157:H7, Campylobacter pylori and hepatitis $\mathrm{C}$ and $\mathrm{D}$ as human pathogens strongly suggest that all human pathogenic organisms have not yet been discovered. If a single pathogen causes Crohn's disease or ulcerative colitis, it must be a novel, poorly cultivatable agent, possibly a retrovirus or an organism replicating intracellularly. An actively replicating agent may no longer be present once clinical disease is manifested, but may be incorporated into the genome (as in hepatitis B and hepatomas) or induce an autoimmune response.

Although specific microbial pathogens do not appear to cause IBD, episodic infections (Table 2) can clearly produce exacerbations of symptoms, which are important to distinguish from spontaneous relapses of IBD so specific therapy can be instituted. C difficile toxin should definitely be assayed in all patients who received antibiotics within several months of symptom exacerbation (1). Recently, toxin-producing $E$ coli have been isolated from several patients with active ulcerative colitis $(8,9)$. Kangro et al (10) demonstrated that $24 \%$ of clinical exacerbations of IBD in children were temporally related to viral and mycoplasma infections, reinforcing clinical observations that upper respiratory infections can cause flare-ups of IBD.

Abnormal luminal constituents: Crohn's disease patients have increased concentrations of anaerobic bacteria, including Bacteroides species (especially B vulgatus) (11), eubacteria and peptostreptococci (12). A provocative prospective longitudinal study by Van de Merwe et al (13) of asymptomatic children of Crohn's disease patients suggests that abnormal anaerobic bacterial profiles may be a risk factor for developing symptomatic Crohn's disease. Small bowel bacterial overgrowth is frequent in Crohn's disease due to surgical loss of the ileocecal valve, distal ileal strictures with partial obstruction and enterocolic fistulas. Post resection recurrence consistently occurs immediately proximal to the ileocolic anastomosis, perhaps related to exposure of the ileum to colonic flora. Although total colectomy cures ulcerative colitis, inflammation within ileal pouches ('pouchitis') appears to be related to overgrowth of anaerobic bacteria, since metronidazole frequently cures pouchitis. Interestingly, clinically significant pouchitis occurs in 15 to $25 \%$ of ulcerative colitis patients, but is very rare or nonexistent in familial polyposis patients (14), raising the possibility of differential host susceptibility to bac- teria or bacterial products or of unique pathogenic anaerobic bacteria in some ulcerative colitis patients. Relatively high frequencies of hepatic, joint and skin inflammation in patients with colonic IBD or small intestinal bacterial overgrowth (jejunoileal bypass) suggest a role for anaerobic bacteria in the pathogenesis of extraintestinal inflammation.

Subtle changes in intestinal microbial flora, undetectable by conventional culture techniques, could lead to profound changes in luminal metabolism, mucosal barrier permeability, concentrations of toxic bacterial products, and cross-reacting antigens which could cause intestinal injury. Stool cultures may isolate morphologically normal $E$ coli or B vulgatus, yet certain strains of these 'normal flora' can silently produce cytotoxins $(8,9)$ or secretagogues, exhibit different adhesins (15), express membrane glycoproteins that cross-react with epithelial cell antigens, or produce mucolytic enzymes (16) which make them pathogenic. Metabolic consequences of alterations of anaerobic bacteria include altered luminal acetic acid/propionic acid ratios, which could change intestinal contents from nutritionally beneficial to injurious, and altered bile acid metabolism and absorption which could lead to damage of epithelial cell membranes. Certain strains of eubacteria produce toxic cell wall polymers (17), while B vulgatus strains have variable priming activity in the carrageenan colitis model (18), demonstrating that 'normal flora' strains can have highly toxic properties.

Increased absorption of luminal macromolecules and bacteria: Patients with active IBD have increased mucosal permeability, allowing uptake of bacterial, dietary and other immunogenic and potentially toxic macromolecules. Crohn's disease patients, and perhaps their asymptomatic relatives, have increased mucosal permeability to inert markers even during quiescent phases of their disease (19), implying that this leakage is a primary abnormality rather than merely a secondary result of inflammation. IBD patients have increased serum anti- 


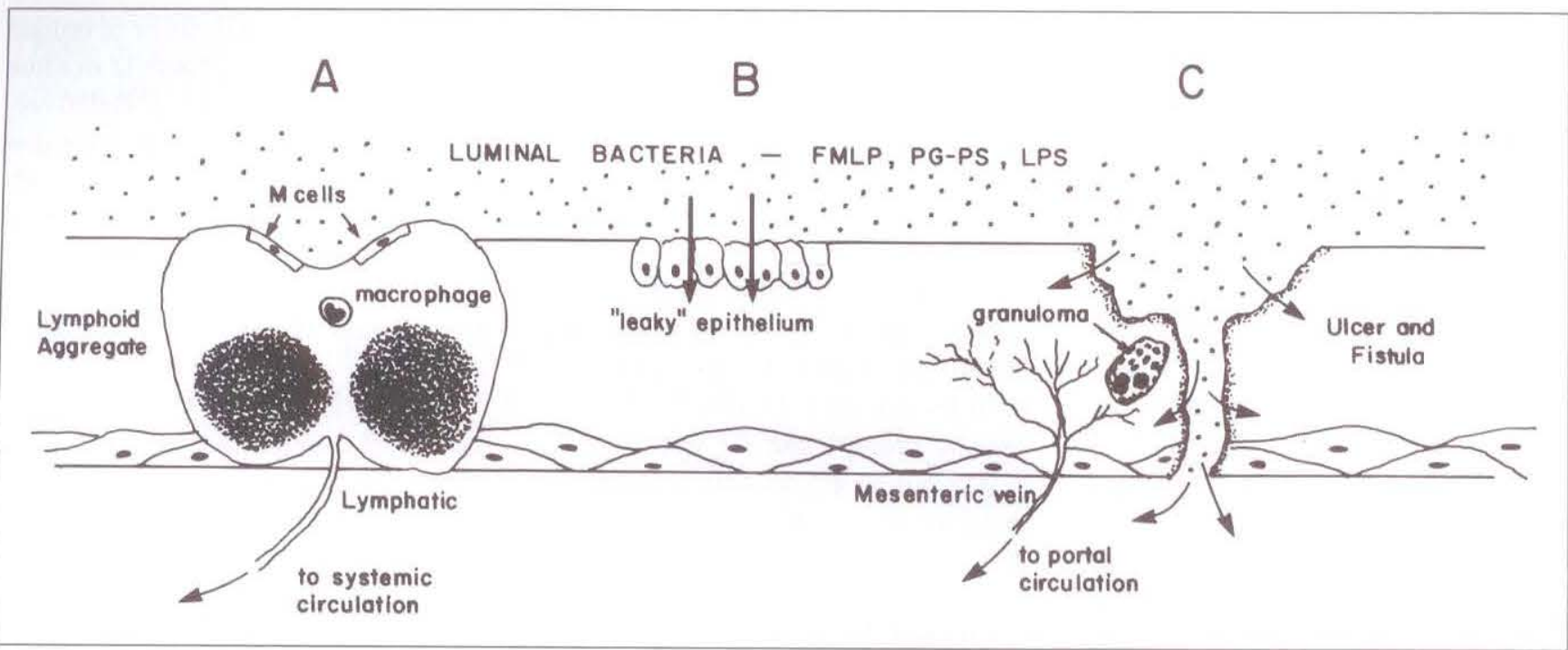

Figure 1) Mechanisms of mucosal uptake of bacteria and bacterial products ( $\mathrm{n}$-formyl-methionyl-leucyl-phenylalanine [FMLP], lipopolysaccharide and peptidoglycan-polysaccharide polymers) present in high concentrations in the distal ileal and colonic lumen. A Specialized epithelial cells ( $M$ cells) over Peyer's patches and organized lymphoid follicles preferentially transport luminal macromolecules in the normal state, initiating a normal mucosal immune response. B Normally the intact epithelium provides a relatively impenetrable barrier, but in nonulcerative inflammation, NSAID treatment or perhaps subclinical IBD, the epithelium is 'leaky', permitting enhanced uptake of luminal bacterial products. C With intestinal ulceration there is secondary invasion of viable bacteria and unrestricted uptake of bacterial products and antigen, further intensifying inflammation. (Reproduced with permission from Sartor RB, Powell DW. In: Field M, ed. Controversies in Gastroenterology, Diarrheal Diseases. New York: Elsevier. [In press])

bodies to many commensal and pathogenic bacterial species (20) and dietary antigens, suggesting a leaky mucosal barrier or increased immunoresponsiveness to luminal antigens (or lack of suppression). Increased IgG and IgM production and enhanced uptake of luminal antigens could lead to intestinal and systemic immune complex deposition, with activation of complement. The earliest visible lesions of Crohn's disease, aphthous ulcers, appear preferentially over lymphoid aggregates, where specialized epithelial cells ( $M$ cells) readily transport luminal macromolecules. According to Shorter's hypothesis (21), neonatal sensitization to luminal antigens could lead to immunologically mediated injury when a later nonspecific break in the mucosal barrier permits entry of relevant antigens.

Viable bacteria also cross the defective mucosal barrier more frequently in Crohn's disease. Ambrose and Keighley (22) cultured enteric bacteria from the serosa or mesenteric lymph nodes from $56 \%$ of intestines resected for Crohn's disease compared with only $17 \%$ of controls. Recently Deitch (23) cultured bacteria from $59 \%$ of mesenteric lymph nodes from patients with bowel obstruction versus $4 \%$ of controls. Cartun and Van Kruiningen (24) using immunofluorescence showed streptococci and $E$ coli adjacent to mucosal ulcers and fistulas, and occasionally within granulomas in at least $56 \%$ of Crohn's disease tissues, thus documenting secondary invasion of inflamed tissues. Certainly increased uptake of dietary and bacterial antigens and secondary invasion of ulcers by replicating bacteria could perpetuate inflammation and cause septic complications in IBD. Primary and secondary mechanisms of mucosal uptake and systemic distribution of bacteria and bacterial products in IBD are illustrated in Figure 1.

Inflammatory response to normal bacterial constituents: Both commensal and pathogenic bacteria produce potent inflammatory molecules, including lipopolysaccharide (endotoxin), peptidoglycan-polysaccharide polymers and $n$-formyl-methionyloligopeptides (F-met peptides, including $n$-formyl-methionyl-leucyl-phenylalanine [FMLP]) $(25,26)$. Lipopolysaccharide, peptidoglycan-polysaccharide polymers and F-met peptides activate polymorphonuclear leukocytes and macrophages/monocytes, while lipopolysaccharide and peptidoglycan- polysaccharide polymers activate the complement, clotting and kinin cascades, serve as mitogens for $\mathrm{B}$ and $\mathrm{T}$ lymphocytes, and stimulate cytokine and eicosanoid synthesis. F-met peptides are potent chemotaxins, while lipopolysaccharide and peptidoglycanpolysaccharide polymers are among the most active inducers of interleukin-1, tumour necrosis factor and other cytokines. These bacterial products frequently work synergistically, for example, lipopolysaccharide primes macrophages and polymorphonuclear leukocytes for triggering by F-met peptides and lipopolysaccharide, while heterologous peptidoglycan-polysaccharide polymers reactivate peptidoglycan-polysaccharide polymer-induced inflammation.

Limited but provocative clinical evidence suggests that bacterial products are involved in the pathogenesis of $\operatorname{IBD}(25,26)$. Serum lipopolysaccharide has been detected in the majority of patients with active Crohn's disease and IBD patients, particularly those with extraintestinal manifestations, have elevated serum antibodies to peptidoglycan. Neutrophils from Crohn's disease patients have increased F-met peptide receptors 
and are more responsive to FMLP (27). It is quite rational to speculate that proinflammatory bacterial products present in the distal ileum and colon in high concentrations could produce chronic inflammation in a susceptible host.

\section{AUTOIMMUNE RESPONSE}

Autoimmunity is an attractive hypothesis for the epithelial cell damage of ulcerative colitis, but is probably not operative in the transmural inflammation of Crohn's disease, which involves many cell types. Antibodies recognizing antigens expressed on normal colonic epithelial cells are present in ulcerative colitis but may be secondary to intestinal inflammation rather than being etiologically significant. Serum from approximately $80 \%$ of ulcerative colitis patients contains antibodies which react with the cytoplasm of normal donors' neutrophils (28). Transient bacterial or viral infections could initiate persistent autoimmunity, yet not be detected by the time clinical manifestations occur. Many patients complain of viral, bacterial or parasitic enteric infections or upper respiratory infections prior to onset of symptomatic IBD and note that nonspecific infections are temporally related to flare-ups (10). Intestinal microbes could induce autoimmunity in IBD by several mechanisms.

Molecular mimicry: Circulating antibodies in ulcerative colitis patients react with both enteric bacteria (enterobacteriaceae) and colonic epithelial cells (1). Intestinal infection or colonization with bacteria, viruses or parasites (either autochthonous flora or pathogens) could stimulate production of antibodies and $\mathrm{T}$ cell clones that cross-react with host epithelial cells or white blood cell antigens. Bacterial heat shock proteins are antigenically homologous to proteins synthesized by injured mammalian cells. Antibodies to heat shock proteins are increased in systemic lupus erythematosus and rheumatoid arthritis patients (29), but are only now being investigated in IBD. Antiviral monoclonal antibodies frequently react with mammalian cell components, particularly intracellular filament proteins, which regulate epithelial cell growth and development, including formation of tight junctions.

Microbial alterations of host antigens or immunoregulation: Altered host antigens, exposed 'hidden' antigens, and enhanced immunoreactivity can also cause autoimmunity. Viral infection can change membrane antigens, while cell injury releases cytosolic or nuclear antigens, for example, anti-smooth muscle antibodies in viral hepatitis. Many viruses, including Epstein-Barr virus, and bacterial cell wall polymers (peptidoglycan-polysaccharide polymers and lipopolysaccharide) are polyclonal B cell activators, while peptidoglycan-polysaccharide polymers are a potent adjuvant. Viruses can diminish suppressor $\mathrm{T}$ cell activity and augment $B$ lymphocyte and helper $T$ cell function. Thus viral infection or bacterial cell wall polymer uptake could nonspecifically enhance immune function, leading to production of autoantibodies or $\mathrm{T}$ cells reacting to epithelial or lamina propria cells.

\section{EXPERIMENTAL ENTEROCOLITIS INDUCED BY BACTERIA AND BACTERIAL POLYMERS}

Endogenous enteric microflora and purified bacterial products reproducibly initiate and perpetuate intestinal and systemic inflammation in experimental animals (30). Similar mechanisms of injury may be involved in the pathogenesis of IBD and its extraintestinal complications.

Endogenous luminal bacteria and their products: Germ-free and broad spectrum antibiotic-treated animals develop markedly attenuated intestinal injury with a variety of experimental injuries, demonstrating the important role of endogenous intestinal bacteria. For example, indomethacin-treated germ-free rats have much less small bowel and colonic injury than conventionalized littermates, and germ-free or metronidazole-treated guinea pigs do not develop carageenan-induced colitis, which requires B vulgatus. Small bowel bacterial overgrowth in rats with surgically created self-filling blind loops of jejunum leads to chronic hepatobiliary inflammation resembling sclerosing cholangitis; these lesions are prevented by metronidazole and tetracycline but not gentamicin or polymyxin, implying a role for anaerobic bacteria. Interestingly, inbred rat strains exhibit differential susceptibility to hepatobiliary inflammation, with small bowel bacterial overgrowth which parallels their susceptibility topeptidoglycan-polysaccharide polymer-induced inflammation. These studies agree with clinical observations of improved Crohn's colitis, extraintestinal inflammation with jejunoileal bypass and nonsteroidal anti-inflammatory drug-induced intestinal injury (31) with metronidazole treatment.

Purified bacterial products: Normal intestinal flora produce $n$-formylated peptides and cell wall polymers which can activate almost every pathway of the inflammatory response. These purified bacterial components produce intestinal inflammation in experimental animals (30). Luminal F-met peptides induce acute intestinal inflammation associated with enhanced ileal mucosal permeability, and undergo enterohepatic circulation. Intravenous lipopolysaccharide produces acute hemorrhagic injury of the mid small bowel and can reactivate peptidoglycan-polysaccharide polymer-induced inflammation. Peptidoglycanpolysaccharide polymers injected into the intestinal wall of rats induce acute and chronic spontaneously relapsing, transmural granulomatous enterocolitis associated with arthritis, liver disease and anemia. Genetically susceptible (Lewis) and resistant (Buffalo) inbred rat strains to peptidoglycan-polysaccharide polymer-induced chronic inflammation have been identified, and enhanced systemic absorption of luminal peptidoglycan-polysaccharide polymers occurs with small intestinal and colonic injury. Purified peptidoglycan-polysaccharide polymers can potentiate indomethacin-induced small intestinal inflammation in germfree rats and acetic acid-induced colonic injury in conventional rats. Systemic injection of peptidoglycanpolysaccharide polymers induces the 


\section{GENETIC FACTORS PROINFLAMMATORY
BARRIER FUNCTION LUMINAL BACTERIA \\ FMLP, LPS, PG-PS \\ BACTERIAL \& DIETARY ANTIGENS \\ BILE ACIDS \\ DIGESTIVE ENZYMES \\ ENVIRONMENTAL \\ INFECTIONS \\ ANTIBIOTICS \\ DIET, SMOKING \\ STRESS, NSAID \\ IMPERMEABLE MUCOSA

PGE $_{2}$, PGI $_{2}$
CORTISOL, IL-1RA
CYTOKINE BINDING
PROTEINS \\ TS LYMPHOCYTES}

Figure 2) The balance between luminal proinflammatory factors and host protective mechanisms. The genetically determined immune response to bacterial products and epithelial barrier function could influence host susceptibility to chronic inflammation while environmental factors could influence initial onset and spontaneous reactivation of inflammation. FMLP $\mathrm{n}$-formyl-methionyl-leucylphenylalanine; LPS Lipopolysaccharide; PG-PS Peptidoglycan-polysaccharide polymers; PG Prostaglandin;IL Interleukin; NSAID Nonsteroidal anti-inflammatory drug; $T_{s} T$ suppressor

acute phase response (fever) and many systemic manifestations (arthritis, liver inflammation, anemia) of active IBD. F-met peptides and lipopolysaccharide derived from many commensal and pathogenic bacteria induce acute injury; the chronicity of inflammation induced by peptidoglycan-polysaccharide polymers varies with different bacterial species. For example, peptidoglycanpolysaccharide polymers from group $\mathrm{A}$ streptococci, certain Eubacterium species and mycobacteria produce protracted granulomatous inflammation, while peptidoglycan-polysaccharide polymers from Peptostreptococcus productus induces only transient injury. Thus, overgrowth of normal flora anaerobic bacteria linked to Crohn's disease could increase concentrations of poorly biodegradable peptidoglycan-polysaccharide polymers capable of causing chronic granulomatous inflammation $(12,13)$.

\section{HYPOTHESIS FOR THE PATHOGENESIS OF CROHN'S DISEASE}

The author proposes that peptidoglycans and other molecules produced by bacteria normally colonizing the distal ileum and colon in high concentrations intermittently leak across the intestinal epithelium during transient infections or toxic injury to produce acute intestinal injury. In the normal host this inflammation resolves without complications. However, in the genetically susceptible individual who lacks appropriate down-regulation of inflammation, more protracted granulomatous inflammation ensues, leading to enhanced uptake of luminal bacterial polymers in a self-perpetuating fashion. Systemic distribution of peptidoglycan-polysaccharide polymers causes arthritis, liver disease, skin lesions, anemia and secondary aberrations of the immune response. Alternative mechanisms resulting in the same pathological reaction are overgrowth of or infection by abnormal luminal bacteria producing poorly biodegradable peptidoglycan-polysaccharide polymers, defective mucosal barrier function with resultant continuous uptake of bacterial products and defective degradation of cell wall polymers.

\section{CONCLUSIONS}

The unrestrained immunological response manifested as heterologous diseases lumped together as IBD is probably a reaction to luminal microbial antigens. It is unclear whether this inflammatory reaction is an abnormal response to a ubiquitous environmental agent (defect of immunoregulation or induction of autoimmunity), an appropriate immune response to an abnormal environmental agent (luminal pathogen or toxic molecule) or perhaps a defect in barrier function allowing continuous and overwhelming uptake of antigens and toxic bacterial products. Present data do not support the hypothesis of a single pathogen as a cause of ulcerative colitis or Crohn's disease, and a specific pathogen causes disease flares in only a minority of cases. The author's hypothesis for Crohn's disease is that abnormal immunoregulation leads to a continuous inflammatory response against ubiquitous bacterial products. Ulcerative colitis is probably caused by an autoimmune response to epithelial cell glycoproteins, perhaps initiated by cross-reactive bacterial an. tigens. Even if intestinal microbial flora are eventually found not to initiate inflammation in ulcerative colitis and Crohn's disease, luminal bacteria and toxic bacterial products probably perpetuate chronic intestinal inflammation and cause the local septic and extraintestinal complications of IBD.

Given the well documented inflam. matory properties of peptidoglycanpolysaccharide polymers, lipopolysaccharide, FMLP, viable bacteria and other phlogistic substances present in high concentrations within the distal intestinal lumen, the critical question is why not every patient develops overwhelming acute and chronic enterocolitis. Figure 2 depicts the delicate balance between proinflammatory and protective forces in the intestine. Normally exclusion of these aggressive factors by a relatively impermeable epithelial barrier and net down-regulation of inflammation prevents injury. However, the fulcrum determining net intestinal inflammation could be shifted by genetic susceptibility or environmental events which could trigger relapses and diminish host resistance. A better understanding of these genetic and environmental factors and indepth investigations of mechanisms of downregulation of inflammation induced by intestinal bacteria and bacterial products will lead to insights into the abnormal immunoregulation of IBD and provide clues for more rational and specific therapies for these disabling conditions. 
ACKNOWEDGEMENTS: Portions of this work were included in the Microecology and Barrier Function section of the Agenda for the 90's, a research outline of the $\mathrm{Na}$ tional Foundation for Ileitis and Colitis. The author acknowledges the significant input of Drs Vinton Chadwick (University of Otago, New Zealand), Martin Blaser (Vanderbilt University), Allan Walker (Harvard University) and Jacqueline Wolf (Harvard University), who were subcommittee members on this project. The author also thanks Shirley Willard for expert typing of the manuscript. Research outlined in this manuscript was supported by the NIH (DK 40249 and DK 34987 ) and the National Foundation for Ileitis and Colitis.

\section{REFERENCES}

1. Gorbach SL. Intestinal microflora in inflammatory bowel disease - Implication for etiology. In: Kirsner JB, Shorter R, eds. Inflammatory Bowel Disease. Philadelphia: Lea and Febiger, 1988:51-64.

2. Hill MJ. Bacteria and inflammatory bowel disease. In: Hill M, ed. Microbial Metabolism in the Digestive Tract. Boca Raton: CRC Press, 1986:211-20.

3. Chiodini RJ. Crohn's disease and the mycobacterioses: A review and comparison of two disease entities. Clin Microbiol Rev 1990;2:90-117.

4. McFadden JJ, Collins JF, Beaman B, Arthur M, Gitnick GL. Mycobacteria in Crohn's disease: DNA probes rapidly and specifically identify different strains. Gastroenterology 1989;98:A462.

5. Seldenrijk CA, Drexhage HA, Meuwissen SGM, Meijer CJLM. T-cellular immune reactions (in macrophage inhibition factor assay) against Mycobacterium paratuberculosis, Mycobacterium kansasii, Mycobacterium tuberculosis, Mycobacterium avium in patients with chronic inflammatory bowel disesase. Gut 1990;31:529-35.

6. Kobayashi K, Blaser MJ, Brown WR. Immunohistochemical examination for mycobacteria in intestinal tissues from patients with Crohn's disease. Gastroenterology 1989;96:1009-15.

7. James SP. Remission of Crohn's disease after human immunodeficiency virus infection. Gastroenterology 1988;95:1667-9.

8. von Wulffen $\mathrm{H}$, Russman $\mathrm{H}$, Karch $\mathrm{H}$, et al. Verocytotoxin producing
Escherichia coli 02:H5 isolated from patients with ulcerative colitis. Lancet 1989;i:1449-50.

9. Ljungh A, Eriksson M, Eriksson O, Henter JI, Wadstrom T. Shiga-like toxin production and connective tissue protein binding of Escherichia coli isolated from a patient with ulcerative colitis. Scand J Infect Dis 1988;20:443. 6.

10. Kangro HO, Chong SKF, Hardiman A, Heath RB, Walker-Smith JA. A prospective study of viral and mycoplasma infections in chronic inflammatory bowel disease. Gastroenterology 1990;98:549-53.

11. Sartor RB. Antibiotics should be used in the management of Crohn's disease. In: Gitnick G, ed. Debates in Medicine. Chicago: Year Book Medical Publishers. (In press)

12. Wensinck F, Custers-van Lieshout LMC, Poppelaars-Kustermans PAJ, Schroder AM. The faecal flora of patients with Crohn's disease. J Hyg Comb 1981;87:1-12.

13. Van de Merwe JP, Schroder AM, Wensinck F, Hazenberg MP. The obligate anaerobic faecal flora of patients with Crohn's. Scand J Gastroenterol 1988;23:1125-31.

14. Becker JM, Raymond JL. Ileal pouchanal anastomosis. Ann Surg 1986;204:375-81.

15. Burke DA, Axon ATR. Ulcerative colitis and Escherichia coli with adhesive properties. J Clin Pathol 1987;40:782-6.

16. Ruseler-van Embden JGH, van der Helm R, van Lieshout LMC. Degradation of intestinal glycoproteins by Bacteroides vulgatus. FEMS Microbiol Lett 1989;58:37-42.

17. Severijner AJ, Hazenberg MP, vandeMerwe JP. Induction of chronic arthritis in rats by cell wall fragments of anaerobic coccoid rods isloated from the fecal flora of patients with Crohn's disease. Digestion 1988;39:118-25.

18. Breeling JL, Onderdonk AB, Cisneros RL. Bacteroides vulgatus outer membrane antigens associated with carrageenan-induced colitis in guinea pigs. Infect Immun 1988;56:1754-9.

19. Katz KD, Hollander D, Vadheim CM. Intestinal permeability in patients with Crohn's disease and their healthy relatives. Gastroenterology 1989;97:927. 31.

20. Blaser MJ, Miller RA, Lacher J, Singleton JW. Patients with active Crohn's disease have elevated serum antibodies to antigens of seven enteric bacterial pathogens. Gastroenterology 1984;87:888-94.

21. Shorter RG, Huizenga KA, Spencer RJ. A working hypothesis for the etiology and pathogenesis of nonspecific in. flammatory bowel disease. Am J Dig Dis 1972;17:1024.

22. Ambrose NS, Johnson M, Burdon DW, Keighley MRB. Incidence of pathogenic bacteria from mesenteric lymph nodes and ileal serosa during Crohn's disease. Br J Surg 1984;71:6235.

23. Deitch EA. Simple intestinal obstruction causes bacterial translocation in man. Arch Surg 1989;124:699-701.

24. Cartun RW, Van Kruiningen HJ, Pederaca CA, Berman MM. Extending the search for microbial agents in Crohn's disease. Preliminary results. Gastroenterology 1989;96:A75.

25. Sartor RB, Powell DW. Mechanisms of diarrhea in intestinal inflammation and hypersensitivity: Immune system modulation of intestinal transport. In: Field M, ed. Controversies in Gastroenterology, Diarrheal Diseases. New York: Elsevier. (In press)

26. Sartor RB. Importance of intestinal mucosal immunity and luminal bacterial cell wall polymers in the aetiology of inflammatory joint diseases. Baillieres Clin Rheumatol 1989;3:223. 45.

27. Anton PA, Targan SR, Shanahan F. Increased neutrophil receptors for and response to the proinflammatory bacterial peptide formyl-methionyl-leucylphenylalanine in Crohn's disease. Gastroenterology 1989;97:20-8.

28. Deurr RH, Targan SR, Landers CJ, Sutherland LR, Shanahan F. Neutrophil autoantibodies in ulcerative colitis: Comparison with other colitides/diarrheal diseases. Gastroenterology 1990;98:A167.

29. Winfield JB. Stress proteins, arthritis and autoimmunity. Arthritis Rheum 1989;32:1497-504.

30. Sartor RB. Animal models of inflammatory bowel disease. In: MacDermott RP, Stenson W, eds. Inflammatory Bowel Disease. Current Topics in Medical Therapy. New York: Elsevier. (In press)

31. Bjarnason I, Turner-Stokes L, Smethurst P, Levi AJ, Gumpel MJ. Metronidazole reduces inflammation in nonsteroidal anti-inflammatory drug (NSAID)-enteropathy. Gastroenterology 1990;98:A439. 


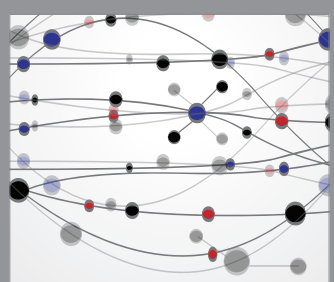

The Scientific World Journal
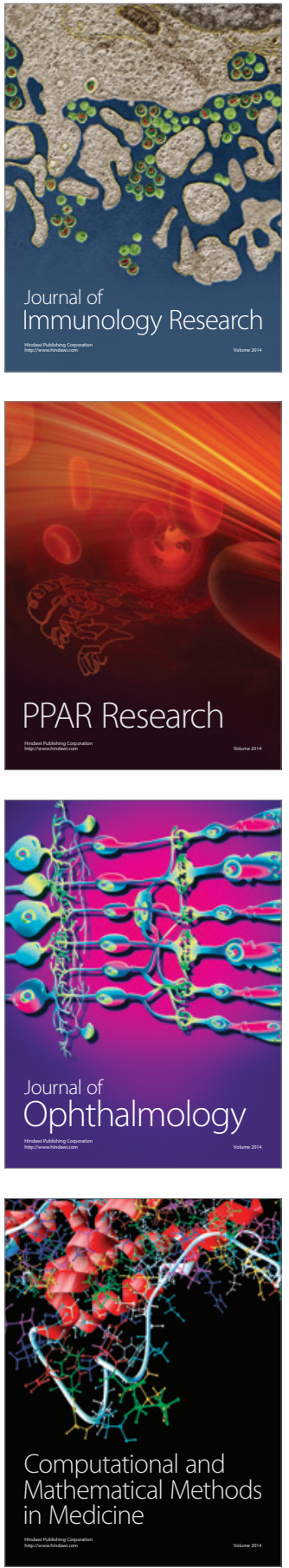

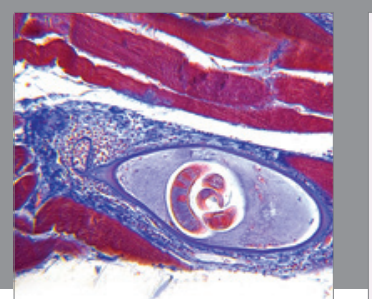

Gastroenterology Research and Practice

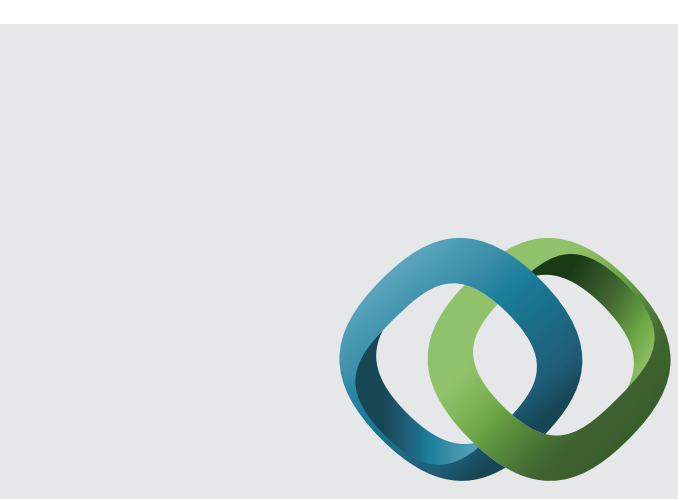

\section{Hindawi}

Submit your manuscripts at

http://www.hindawi.com
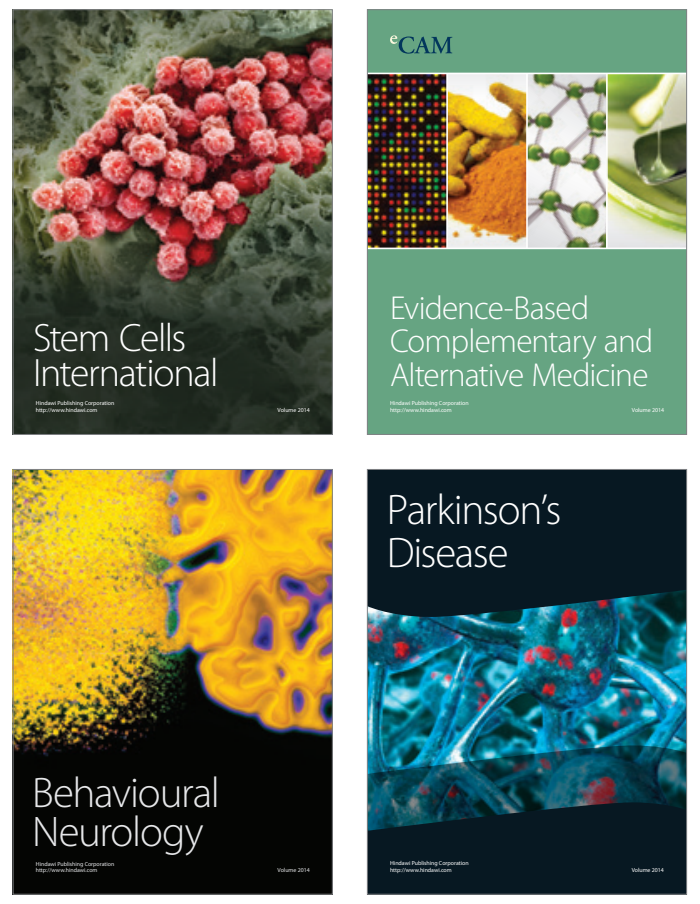
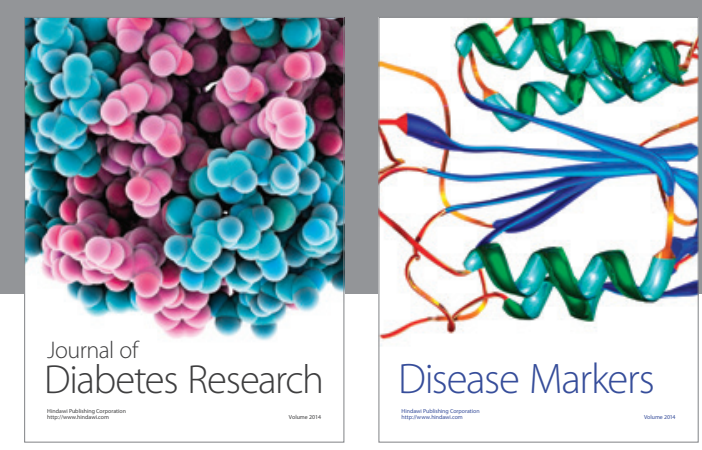

Disease Markers
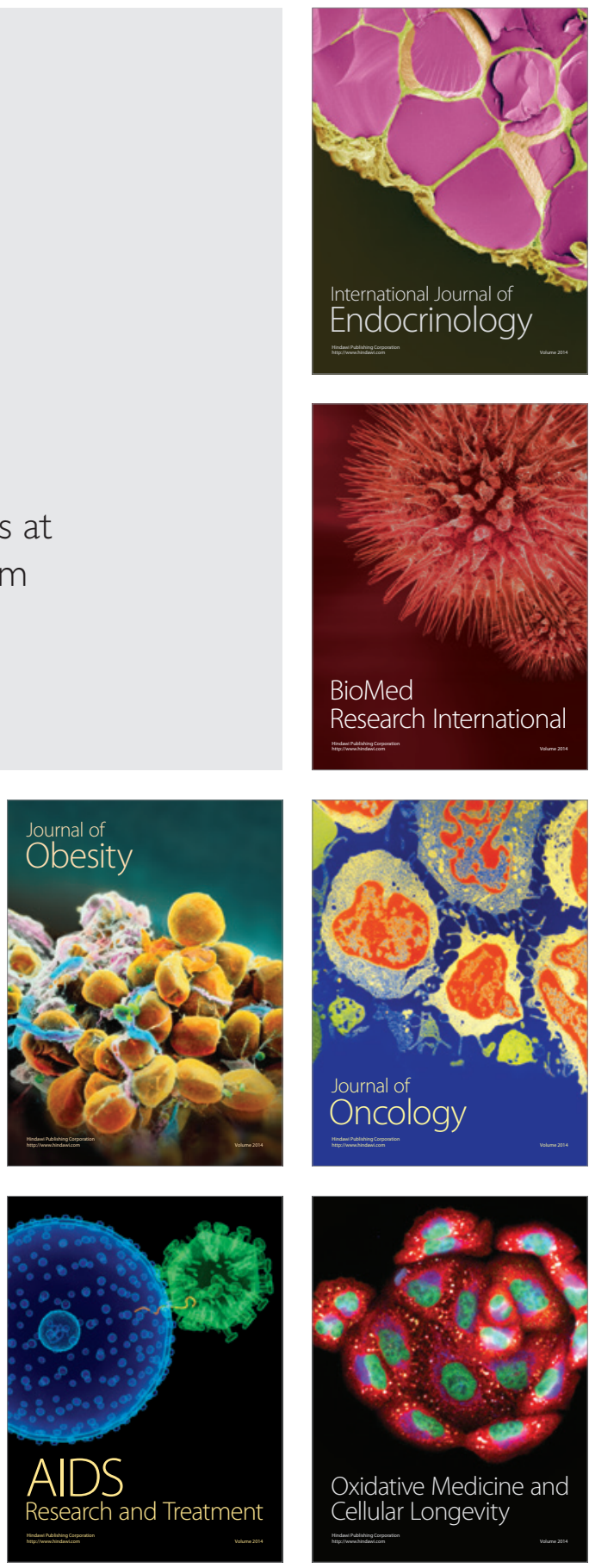